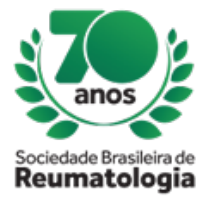

\title{
EVALUATION OF RESPIRATORY MUSCULAR STRENGTH, SIX-MINUTE WALK TEST AND QUALITY OF LIFE IN PATIENTS WITH SYSTEMIC SCLEROSIS
}

Luciana C Palhares (Universidade Estadual de Campinas/Unicamp, Campinas, SP, Brasil), Ellian Rayrini Souza Lima (Universidade Estadual de Campinas/Unicamp, Campinas, SP, Brasil), Suziane Regina Surian (Universidade Estadual de Campinas/Unicamp, Campinas, SP, Brasil), Zoraida Sachetto Sachetto (Universidade Estadual de Campinas/Unicamp, Campinas, SP, Brasil), Ana Paula Toledo Del Rio (Universidade Estadual de Campinas/Unicamp, Campinas, SP, Brasil)

\section{BACKGROUND}

Systemic sclerosis (SS) is a chronic and autoimmune disease of multifactorial origin and that can affect the lungs and heart with a high morbidity and mortality. This study aims to relate muscle strength, distance achieved during the six-minute walk test (6MWT), and quality of life (QOL) in SS patients.

\section{MATERIALS AND METHODS}

Fifteen patients with SS diagnosis, followed by the rheumatology discipline and the physiotherapy of a university hospital were evaluated. Mean age was $52.53( \pm 8.03)$ years, $67 \%$ female. We performed respiratory muscle strength (Pimax and Pemax), 6MWT and SF-36 QOL questionnaire. Accepted by the Research Ethics Committee of Unicamp CAAE: 72365017.4.0000.5404.

\section{RESULTS}

The results show that Pimax has poor correlation with the SF-36 domains. In relation to Pemax, the domains that presented moderate linear correlation were CF (0.31), LAF (0.45) and SM (0.32). The functional capacity had a moderate correlation with the LAE (-0.39) and DOR (0.59), and 6MWT domains.

\section{CONCLUSION}

Pimax had no correlation with 6MWT and QOL. Patients with higher Pemax values showed better functional capacity, physical aspects and mental health in the QOL. Those with lower pain and better emotional aspect in the QOL went longer distances during the 6MWT. 